\title{
Architecture of Energy Internet and Its Technologies in Application Reviewed
}

\author{
Yingya Zhou, Weidou Ni, and Zhao Zhu
}

\begin{abstract}
The increase of distributed energy, deregulation of energy market together with the growing pressure from energy consumption resulted climate change urges a transformation of the energy sector. The dumb centralized grid marches on a metamorphosis to a smart, distributed grid and a diversity of new market roles, business models and technologies are spawned. The other shore of this revolution is called Energy Internet or Internet of Energy. The present work proposes architecture of Energy Internet as a tool of categorization and presents the state-of-art related technologies and use cases based on a wide range of sources including academic papers, project reports, policies and press information.
\end{abstract}

Index Terms-Energy Internet, architecture, review.

\section{INTRODUCTION}

With the liberalization of energy market, increasing concern about climate change and the resulting growing use of renewable energy as well as the decentralization of energy production, the energy sector is undergoing a paradigm transform in three main aspects:

- Market roles: from vertical integrated monopolic utilities to regulated competition in transmission and distribution together with deregulated competition in generation and retail.

- Control and information: from centralized control with few information and communication technology (ICT) to hierarchical distributed self-governance with the aid of ICT.

- Energy supply - from concentrated scheduled production with one-way transmission to distributed dynamic production with bidirectional transmission.

The merge of information technology and energy sector inspired a new term "Energy Internet", after the prominent American economist and macro-economic forecaster Jeremy Rifkin pinpointed in 2011 in his book The Third Industrial Revolution that hundreds of millions of people will produce their own renewable energy in their homes, offices, and

Manuscript received September 10, 2015; revised May 4, 2016.

Yingya Zhou is with the State Key Lab of Power Systems, Department of Thermal Engineering, Tsinghua-BP Clean Energy and Research and Education Center, Tsinghua University, 100084 Beijing China. She is also with Chinese Association of Renewable Energy in Germany e.V., 12683 Berlin, Germany (e-mail: zhouyy12@mails.tsinghua.edu.cn).

Weidou Ni is with the State Key Lab of Power Systems, Department of Thremal Engineering, Tsinghua-BP Clean Energy and Research and Education Center, Tsinghua University, 100084 Beijing China (e-mail: niwd@tsinghua.edu.cn).

Zhao Zhu is with MIT Sloan School of Management, Cambridge, MA 02142, US. She is also with Chinese Association of Renewable Energy in Germany e.V., 12683 Berlin, Germany (e-mail: zhaozhu@ @it.edu). factories and share green electricity with each other in an "Energy Internet" just like we now generate and share information online [1].

The difference between the terms Smart Grid and Energy Internet is noteworthy. Some may take Energy Internet (EI) as a nick name of Smart Grid (SG) [2]. It is however, more widely accepted that Energy Internet encompasses a more comprehensive scope than Smart Grid [3]-[5]. The topological relationship between the two is basically that one the one side, Energy Internet includes both Smart Grid, which concentrates at the automation of the infrastructure and the superstructure like market services. On the other side, Energy Internet covers the whole spectrum of energy demands including electricity, heating, gas and mobility while Smart Grid targets only at electricity.

The vision of Energy Internet has received increasing attention from governments of different countries, giving rise to new innovative applications, technologies and use cases developed by various institutes and initiatives as well as during large to mega pilot projects supported by the authorities, academia and industries.

From 2002 to 2014, 459 SG/EI projects, including Research and Development (R\&D) projects as well as Demonstration and Deployment (D\&D) projects, have been launched in the European Union Member States (EU-28) plus 19 other non-EU European countries, amounting to 3.15 billion euros investment, $50 \%$ of which originates from France, United Kingdom, Germany and Spain [6]. Denmark has the highest investment in SG/EI projects per capita; France and United Kingdom have the largest average budge per project; Germany has the highest cumulated number of projects and highest number of organizations involved in SG/EI projects (200). The EU definition and the projects of Smart Grid are oriented more towards a user-centric and output-focused energy market, production, transmission and consumption, thus actually corresponding to the broader concept of energy internet. The six "E-Energy" projects founded by the German government during 2008 and 2013, which were announced by the Federal Chancellor Angela Merkel as beacon projects, addressed directly the objective of creating "Internet of Energy" in model regions where ICT enhancing the efficiency and environmental compatibility of power supply and enabling a digital active energy marketplace was demonstrated [7].

In the US, with passage of Energy Independence and Security Act of 2007, 100 million dollars were set out to fund the modernization of power grid. Further support with the passage of the American Recovery and Reinvestment Act of 2009 set aside 4.5 billion dollars to fund for 100 projects in Smart Grid development, deployment and worker training. 
For the research of the envisioned FREEDM system, which is also called "Internet for Energy", FREEDM system center was established in 2008 by the National Science Foundation. The US definition of Smart Grid stresses the modernization of the transmission and distribution system to maintain a reliable and secure electricity infrastructure [8].

As the world's largest consumer of energy as well as $\mathrm{CO}_{2}$ emitter, facing the continuing urbanization and growth in energy demand, China rolls out a massive build-out of renewable energy resources as well as combined heat and power, hence a tremendous need for grid expansion. According to the Smart Grid Plan by the national utility, 250 billion dollars had to be invested in the upgrade of power infrastructure between 2010 and 2015 and another 240 billion dollars between 2016 and 2020 will be added to smart grid projects [9]. The Chinese Smart Grid, therefore, emphasizes national ultra-high voltage transmission networks. As an extension of the Chinese Smart Grid concept, the so-called "Global Energy Internet" was proposed by the chairman of the Chinese State Grid Corporation, which plans a global super grid to share green electricity [10].

Research, development and deployment of Energy Internet is supported and promoted worldwide. New technologies and use cases of Energy Internet are emerging and maturing, the results of which have been published in academic articles but also more in thousands of project reports. A structural overview of the diverse technologies in Energy Internet is, nevertheless, absent. It is therefore the purpose of this paper to provide a practical overview by delineating an architecture of Energy Internet filled with state-of-art technologies and use cases.

\section{ARCHITECTURE OF ENERGY INTERNET AND APPLICATIONS}

For the purpose of presenting the technologies and use cases in a structural way instead of a mixed long list, an architecture of Energy Internet is first proposed, which is constructed with the reference of the Smart Grid Architecture Model (SGAM) by the European Commission [11], the Local Area Grid concept by CIMEG of the US [3], the FREEDOM system by NSF FREEDM Systems Center of the US [12] and the Framework for Smart Grid Interoperability provided by NIST of the US [13].

The Energy Internet architecture is constructed by six layers, shown in Fig. 1. From top to bottom are Business Layer, Use Case Layer, Operation Layer, Communication Layer, Interface Layer and Appliance Layer. A Data Exchange from Business Layer all the way through to Interface Layer represents as the communication channel between layers. The Appliance Layer needs interface to exchange information with other layers so that it is not connected to the Data Exchange.

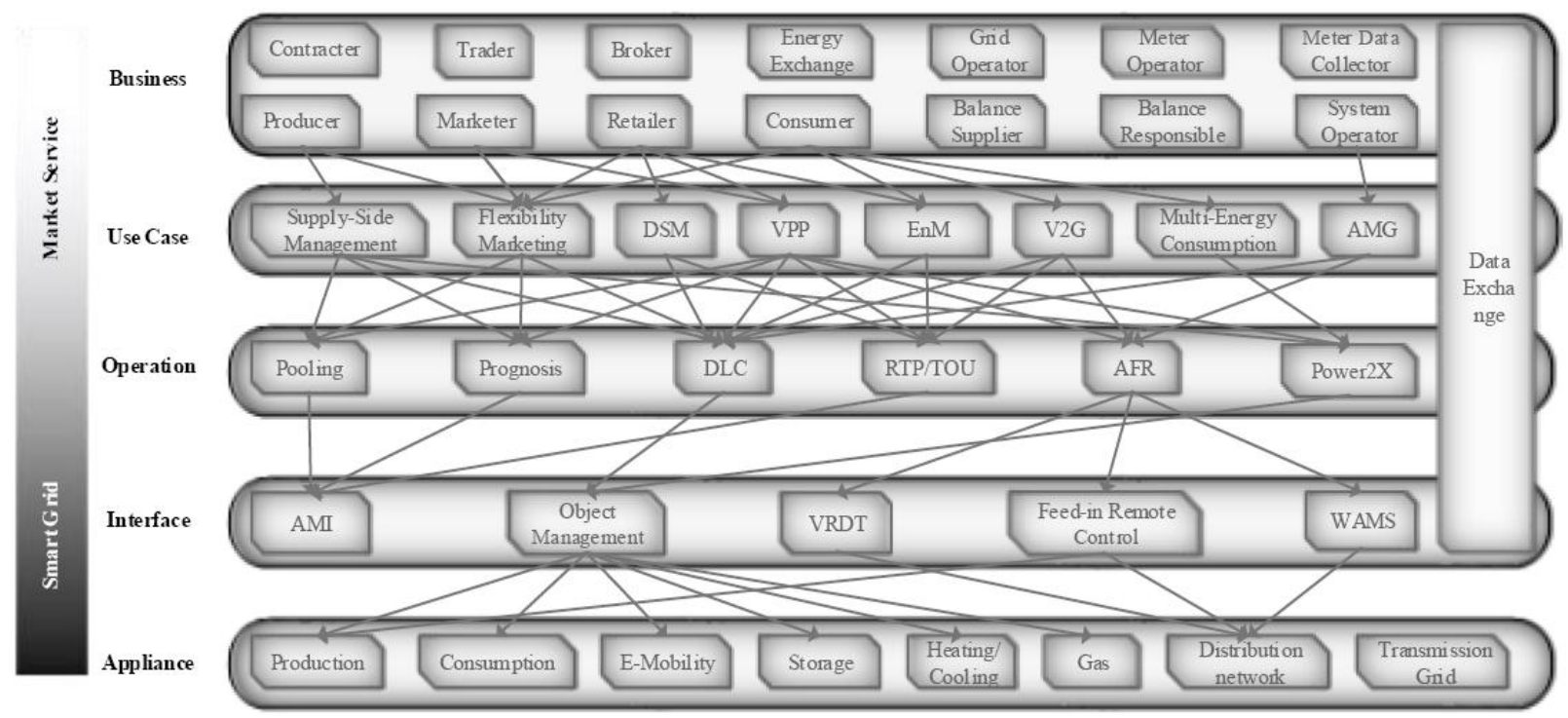

Fig. 1. Architecture of energy internet.

The Appliance Layer, Interface Layer and part of Operation Layer compose Smart Grid while Business Layer, Use Case Layer and the other part of Operation Layer compose energy services. Correspondingly, it is clear that Energy Internet is a combination of Smart Grid and energy services.

In the following, each layer and the components in the layers will be introduced.

\section{A. Business Layer}

A bunch of market roles come into being after the liberalization of energy market. Different roles interact with each other to conduct energy trading and provide services, which will influence all the way down to the physical energy flows in the Appliance Layer.

The primary business in the energy market is to trade energy between producers and consumers. Therefore the primary roles are:

- Energy Exchange: A party that operates the energy exchange platform and determines market price.

- Producer: A party that produces energy.

- Retailer: A party that bulk purchases energy on the market and sells to consumers.

- Consumer: A party that consumes energy.

- Gird Operator: A party that constructs and maintains the grid and provides transmission capacity.

Electricity, as a special commodity, cannot not be massively stored and requires a real-time balance between 
supply and demand as well as an array of essential technical coordination such as reactive power supply and frequency control. The following roles are needed for the unbundling and matching of contracted energy and realized energy:

- System Operator: A party responsible for a stable power system operation and electricity quality

- Balance Supplier: A party that supplies reserve energy

- Balance Responsible: A virtual energy volume account consolidated by supplies and consumers that serves as clearing unit within which the contracted and realized quantities of energy products are balanced. Any physical imbalance will be compensated by System Operator dispatching balancing energy. The cost of balancing energy will be billed to the Balancing Responsible. The mechanism of Balancing Responsible makes possible the unbundling and matching of energy transactions and physical energy flows in face of supply and demand fluctuations by motivating market roles to balance within them.

With the increasing number of distributed energy producers and market participants, more roles of intermediaries come to refine the trading process:

- Trader: A party that executes energy transactions for other market roles

- Broker: A party that conveys trading information between buyers and sellers

- Marketer/Producer Aggregator: A party that sells energy on the market on behalf of small energy producers

- Contractor: A party that provides financing, projecting as well as if applicable, operating and maintaining of energy facilities. Depending on the forms of contracting, the right of operation, use and ownership are allocated either to contractor or contracting customers.

The higher requirements of data acquisition and information transfer for devices like Smart metering bring into life the following roles:

- Meter Operator: A party responsible for installing and maintaining physical meters.

- Meter Data Collector: A party responsible for meter reading.

As the work segmentation continues, new market roles hive off from primary roles to serve as outsourcers of a certain service, including but not limited to:

- Billing Agent, Portfolio Management, Tariff Management, Contract Switching Service and Energy Management Consulting.

It is important to notice that a market participant can take on multiple market roles while a market role can also be fulfilled by multiple participants, to name a few examples:

- Presumer is a participant that are both customer and producer;

- Energy Supplier can be a participant that is both producer and retailer;

- Grid Operator often takes on the role of Meter Operator;

- In the US, Independent System Operator (ISO) and Regional Transmission Operator (RTO) carry out the both the roles of System Operator and Energy Exchange.

Moreover, not all the roles have to exist in a regional market. For example, Balancing Responsible is present in most of the countries in Europe but not implemented in the US
[14]

\section{B. Use Case Layer}

The transaction and interaction between market roles in the Business Layer are realized by various use cases, in other words, business models.

\section{1) Supply-side management (SSM)}

Supply-Side Management is to allocate generation capacity for an optimized profit to provide different products, including power generation and ancillary service. For example, according to the market price of different products, the power generation capacity can be dynamically allocated to power generation and reserve provision, together with heat storage for a more flexible power generation. DFIG based Wind turbines can be allocated to active and reactive power generation [15]. It has been concluded from some pilot projects that Supply-Side Management can make a contribution to peak clipping and valley cliffing to the similar extent of Demand-Side Management [7].

\section{2) Flexibility marketing}

In comparison to the intermittent, indispatchable renewable generation, fossil power plants, combined heat and power, biomass power plant, storage system and power to gas systems distinguish themselves as dispatchable capacity. To compensate the difference between forecasted power and generated power or between contracted power and realized power, Balance Responsible, Retailers or even Producers can buy "Flexibility of power", that is, to reserve a certain range of capacity that can be dispatched whenever in need. Due to high penetration of intermittent renewable generations and a competitive energy market, many market participants in Germany start to procure or sell "Flexibility" as a commodity [16]. It is also shown that through exploiting the flexibility of energy generation facilities, the demand of grid expansion can be reduced [7].

\section{3) Demand side management (DSM)}

Demand-Side Management (DSM) is the planning and implementation of activities designed to influence customer uses of electricity in ways that will produce desired changes in the utility's load shape [17]. While in 1990s the concept of DSM was present in only a few studies, the interest for DSM rises dramatically since 2010 [18].

The use case DSM can be realized in 2 ways in the Operation Layer: Real-Time Pricing (RTP) and Time of Use (TOU) and Direct Load Control

\section{4) Virtual power plant (VPP)}

A virtual power plant is an aggregation of one or more assets of distributed generators, controllable loads and storage systems for the purpose of making contracts in the wholesale market and offering services to system operators like a conventional power plant [19], [20]. The principal of VPP is to use the variability of energy supply to hedge the variability of energy demand as well as to balance the variability of indispatchable energy sources by dispatchable energy sources. The logic behind this principal is that dynamic supply can be seen as negative dynamic load while dynamic load can be seen as negative dynamic supply. Three forms of VPP exist in practice: Supply-Side VPP, 
Demand-Side VPP and Mixed Asset VPP, with the last form being the ultimate goal. Similar to the trend of DSM, while VPP is hardly a new term, interest for VPP from industry and academia thrives only over the last few years. A diversity of VPP vendors nowadays provide VPP software to various energy market participants, with an estimated market value of 1 billion dollars [21]. While Demand-Side VPP dominates the US market, Supply-Side VPP takes lead in European market. VPP has gone through the demonstration phase and is deployed on the energy market for business. It is even envisioned that the entire country of Germany could be completely powered by a diverse blend of complementary renewable energy resource through VPP [22].

\section{5) Vehicle to grid (V2G)}

Plug-in electric vehicles (EV) can be managed to balance the fluctuation of renewable electricity sources by adjusting charging or discharging power to the grid. V2G is practical based on the fact that most private EVs are driven only 1 hour per day so that EVs can actually serve as mobile battery when they are parked idly in the rest 23 hours of the day [23]. V2G can be realized in three ways in the Operation Layer: Direct Load Control, RTP/TOU or Automatic Local Frequency Regulation.

V2G through Direct Load Control requires two-way communication so that the status of EVs can be acquired, based on which System Operator can directly send control signal of charging or discharging. Although Direct Load Control seems to enable System Operator to dispatch EVs just like other conventional power plants and pumped hydropower station, dispatching EVs is unfavorable due to two fundamental differences from conventional dispatchable power: One the one side, conventional power plants are of large capacity and connected directly to the transmission grid while EVs are dispersedly connected to distribution grids where far less information is available. It is more complex for System Operator to dispatch EVs in distribution gird level. On the other hand, restrictions on battery availability go back on the main purpose of EVs that they should provide mobility at the will of owners [24].

$\mathrm{V} 2 \mathrm{G}$ through RTP/TOU is an indirect way of control. Customers or devices programmed with customized reaction criteria decide, on receiving the price signal, whether to react to the incentive or not. One of the advantages of indirect control is that bidirectional communication system in the backend of EVs is not a must. Indirect control of V2G has went through R\&D phase and already finds its application in many regions [25]. However, due to the long reaction time, V2G via indirect control can only provide peak load reduction or minute reserve, the marginal benefit of which is limited. The fast charging and discharging ability of EVs cannot be fully deployed through RTO/TOU for more valuable ancillary grid service.

V2G through Automatic Frequency Regulation is to use internal sensors of EVs to monitor the voltage and frequency signals at the charging point and adjust the charging mode automatically to provide frequency regulation. This way saves bidirectional communication infrastructure and the attention of customers. Presently V2G through Automatic Frequency Regulation is under R\&D [26] and demonstration project phases [27], [28].

Recently, aggregation of $\mathrm{V} 2 \mathrm{G}$ availability to provide ancillary service to System Operator is proposed as a new way of V2G [29]. Aided with advanced capacity estimation algorithm, aggregators can pool the dispersed dynamic availability of EVs and sum up to a contracted volume of ancillary service.

\section{6) Energy management (EnM)}

Energy Management is already implemented extensively worldwide. According to ISO 50001, Energy Management is defined as "Set of interrelated or interacting elements of an organization to establish energy policy and objectives and to achieve those objectives" [30]. The term Energy Management covers both the technical resources needed, for example, hardware and software like Energy Management System (EnMS) but also the organizational and information structures required for implementing EnMS. EnM helps to save energy in ways of monitoring, controlling and conserving energy in a building, organization or process. EnMS has long been employed by high energy-demand. However, the development and spread of EnMS for industrial and commercial applications starts to speed up over the last few years due to the stress on energy efficiency from governments. Since the end of 2012, an European Union Energy Efficiency Directive takes effect with a variety of measures to ensure a $20 \%$ increase of energy efficiency till 2020, among which are the decrees that the member states should save $1.5 \%$ of energy every year and large companies are obligated to conduct energy audit. Home Energy Management also begins picking up momentum since the initial jolt of Google's acquiring Nest Lab in 2014.

Energy Management may employ Direct Load Control and Power-to-X in the Operation Layer.

\section{7) Mulit-energy consumption}

Industries who have self-owned power plants on site or can run on both gas and electricity, including metallurgy and chemical industries, can employ the Multi-Energy Consumption mode, that is, to switch dynamically to less expensive energy source. Some of the chemical industries can also benefit from the gas storage in their process in face of high electricity price during peak load time. Multi-Energy Consumption is worthy when intermittent renewable power sources increases and electricity price on the spot market becomes more volatile. In a broader sense, hybrid $\mathrm{EV}$ s is also multi-energy consumers.

\section{8) Autonomous microgrid (AMG)}

Microgrid is defined officially by Department of Energy of US as a group of interconnected loads and distributed energy resources (DER) with clearly defined electrical boundaries that acts as a single controllable entity with respect to the grid [and can] connect and disconnect from the grid to enable it to operate in both grid connected or island mode.

The Autonomous Microgrid is a system that is autonomously operated depending on the grid and internal load condition, without operator's intervention [31]. The motivation of AMG is that in face of rapid increase in intermittent renewable energy sources fed in distribution network, regulation of distribution network becomes so 
complicated that manual operation is soon unable to satisfy all the regulation requirements.

AMG can be realized in various degrees, from real-time monitoring, fault diagnose and self-healing, to automatic frequency and voltage regulation, transformer control to integration of DSM and communication between AMGs.

Currently AMG is under R\&D [31], [32] and pilot project [33] phases.

\section{Operation Layer}

Operations in the Operation Layer are the basic components of functions to fulfill use cases.

\section{1) Pooling}

Pooling is to aggregate dispersed energy, capacity, availability, flexibility or the demands of them for the benefit of economic of scale. Pooling originates from gathering power generations to form a power pool with a single agreement that all utilities can join [34]. As energy generation becomes more fragmented due to distributed energy and the emerging use cases of DSM, VPP and Flexibility Marketing, demands and flexibilities are also getting pooled.

\section{2) Prognosis}

Due to the intermittency of renewable energy supply, various forms of prognosis are needed. Supply and demand prognoses, both linked with weather forecast as well as sociodemographic and generation distribution data, are essential for System Operator to plan grid operation mode and check congestion proactively. Suppliers, Retailers, Aggregators and Traders also need supply and demand prognoses to deduct energy price prognosis, which is indispensable for pricing, procurement, investment or hedging strategies. System Operator and Grid Operator also need the prognosis of network condition, often integrated in the asset management system, to schedule maintenance. Prognosis system is already a mature technology and available on the market but further development is needed in terms of accuracy and comprehensiveness [35].

\section{3) Real-time pricing (RTP)/time of use (TOU)}

RTP and TOU are both pricing strategies where energy price changes in time to reflect the supply and demand balance. The difference is only that RTP is often synchronized with real-time spot market price while TOU only varies between a few fixed price levels during a few fixed time periods.

Energy producers are motivated to employ Supply-Side Management to generate power in a way of tracking the demand when they have to sell energy at RTP instead of fixed feed-in tariff. That's why the German government amended in 2012 the Renewable Energy Act to encourage direct marketing instead of fixed feed-in tariff for renewable electricity. It is reported that after the introduction of direct marketing, the renewable electricity producers switch off electricity production or store electricity in battery when negative power price appears on the spot market [36].

Consumers are motivated to shift load from peak time to valley time after information about supply and demand is passed on to consumers by RTP or TOU. Though theoretical and empirical analyses has shown a large load shift potential, RTP suffers from higher cost for communication and smart control than Direct Load Control. It is reported that in the US during 2008 and 2010 despite an 85\% increase in advanced metering, the number of entities offering RTP and TOU decreased while DLC seems to be leading the way [37].

RTP/TOU influences the consumption behavior in two ways: either the price is shown on a consumer terminal and consumers switch manually the loads or the price is passed on to Energy Manager who decides to switch load automatically according to pre-configured rules.

\section{4) Direct load control (DLC)}

Direct Load Control is to adjust the load of appliances typically via radio signal or power-line carrier to pair with intermittent renewables such as wind power or during critical events and peak demand. Typical applications are air-conditioners, water heaters, swimming pool pumps, ice house and industries with high energy consumption like aluminum production. DLC programs in household have been vastly applied in the US while in European counterparts the development of DLC is small to moderate due to regulatory barriers [38].

\section{5) Automatic frequency regulation (AFR)}

Automatic Frequency Regulation (AFR), which is also called primary reserve in Europe or frequency responsive spinning reserve in the US, is to automatically provide capacity within 0 to 30 seconds to stabilize the frequency of power grid. Traditionally AFR is conducted by generators and pumped hydropower stations equipped with automatic generation control (AGC), which can change outputs quickly (MW/min) to track the moment-to-moment fluctuations in loads and correct for the unintended fluctuations in generation.

The trend is, however, that there is increasing demand for AFR due to the rising renewable power sources but decreasing spinning reserve provided by the generators due to shut-downs of conventional power plants. As a substitute, battery storage, V2G [39], Direct Load Control of household appliances [40] or industries such as aluminum and Chlor-Alkali production [41] come into play to provide AFR.

\section{6) Power-to- $X$}

Since electricity cannot be stored in the grid and must be consumed at the point it is generated, surplus electricity is transformed into other energy forms, which is called Power-to-X. Included are

- Power-to-Gas, where water is electrolyzed into hydrogen and oxygen and if necessary, the hydrogen is further synthesized into methane so that electricity is transformed into gaseous fuel;

- Power-to-Fuel, where hydrogen produced by Power-to-Gas is taken as fuel or synthesized into other fuels;

- Power-to-Chemical, where hydrogen produced by Power-to-Gas is further synthesized into methanol and other chemical products. Another meaning of Power-to-Gas is that chemical industries consume the surplus electricity and store the chemical feedstock for production later;

- Power-to-Power, where electricity is converted into chemical or mechanical energy that are reconverted later 
into electricity. Power-to-Power is essentially electricity storage;

- Power-to-Mobility, where electricity is stored in the batteries of EVs;

- Power-to-Heat, where electricity is converted into heat by heat pumps or electric boilers.

A systematic environmental comparison of various Power-to-X based on life cycle assessment was made in 2014, showing that the highest reduction of global warming is achieved by Power-to-Heat via heat pump with hot water storage and Power-to-Mobility, followed by Power-to-Power. The lowest $\mathrm{CO}_{2}$ mitigation cost is achieved, however, by Power-to-Power [42].

\section{Interface Layer}

Functions in the Function Layer are translated to commands and signals, which go through interfaces to the destination appliance in the Appliance Layer. Conversely, the status of appliance is "felt" and collected by an interface and sent to Function Layer. In a sense, the Interface Layer is the sensory of Appliance Layer.

\section{1) Advanced metering infrastructure (AMI)}

Advanced Metering Infrastructure (AMI) means systems that measure, collect, control and analyzes energy usage at consumers' sites and send the consumption data to utilities, network operators and customers themselves. An AMI system, as illustrated in Fig. 2, is composed of the following modules:

- Metering which registers energy consumption and production in a real-time or near-time base and sends the data,

- Analysis and display which receives and processes the data as well as shows the analysis of energy consumption,

- Energy manager which receives RTP/TOU or is preprogrammed to conditionally generate control signals to appliances and monitor the status of appliances,

- Smart meter gateway which exchanges data and signals with externals and if necessary, connects the inner components of AMI,

- Cloud databank which saves the historical data accessible to externals and customers.

Smart Meter, as often heard but the definition of which varies from product to product and from country to country, can be the metering module combined with one or more of other modules.

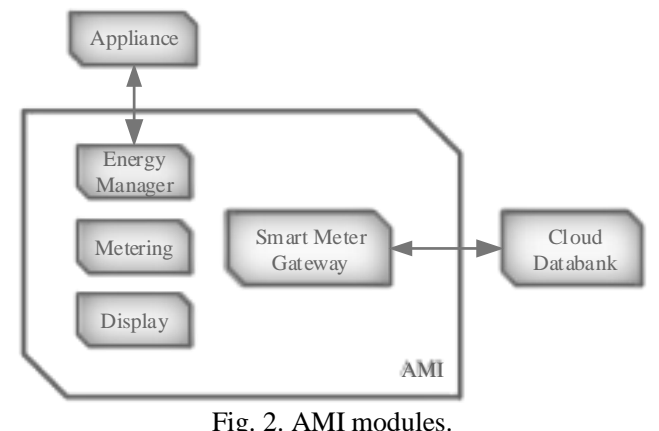

Depending on data security settings and connection infrastructure, modules can be designed to connect in different ways. For example, the data collected by the metering can be sent to gateway that distributes the data to display, energy manager and cloud databank. Alternatively, the metering can directly transfer the data to display and energy management while the smart meter gateway only serves as the channel to bidirectionally communicate to externals.

AMI structure can also be easier or more complex. One version in Germany sets the metering and DSM separated due to security considerations, resulting in one more gateway through which RTP/TOU should be sent directly to Energy Manager. Various designs and structures of AMI have been developed in pilot projects in Germany, each is found to have its pros and cons [7].

Putting aside the design issues, AMI can benefit various parties:

- Customers expect to save energy due to the visualization of energy consumption and analysis as well as to save energy cost via DSM;

- Utilities expect to save the labor cost of manual registration of metering data , to offer new value-added services as well as to improve the demand prognosis for a better purchasing strategy ;

- System Operators expect to know the network condition better based on the demand data.

Additional functions such as communication between electricity, gas and water meters as well as billing could also be desired.

It is here worthwhile to mention that according to experience from pilot projects, the visualization of energy consumption on the display itself can already encourage consumers to save $10-20 \%$ of energy. DSM with aid of AMI can realize another up to $20 \%$ potential of consumption shift in time [7].

AMI has been massively rolled out in Europe, the US and other countries. Despite technical issues, data security and standardization and investment are possible aspects hindering the further spread of AMI [43].

2) Wide area measurement system (WAMS)/ phase measurement unit (PMU)

Wide Area Measurement System is an advanced grid dynamic performance monitoring system incorporating multiple Phase Measurement Units (PMU) and Phasor Data Concentrators (PDC), together with information tools, Global Positioning System (GPS) and operation infrastructure. The purpose of deploying WAMS is to handle data collection, sharing coordinated control actions at a high granularity and over a wide area, which makes the grid more efficient and reliable [44]. While the concept of WAMS was proposed in 1980s and the first demonstration project was launched in 1995 in the US, WAMS finds its commercial deployment only over the last decade due to the trend of Smart Grid [45].

\section{3) Feed-in remote control}

Traditionally solar power plants and some wind power plants were installed in a "Fit and Forget" way, since small share of renewables would not impact the grid much. However, with increasing share of intermittent renewable power, electricity surplus and imbalance between supply and demand occur more often, as shown by frequenter occurrence of negative electricity wholesale prices both in the US and EU 
power exchanges. Through Feed-in Remote Control the renewable power plants are able to be controlled to reduce power generation or be totally switched off so that producers will not suffer from negative prices. Moreover, Feed-in Remote Control makes possible a better integration of renewable powers into VPPs [46]. It is also possible to add the function of remote control of inverter so that renewable power plants can also provide reactive power to support the grid.

\section{4) Voltage-regulated distribution transformers (VRDT)}

Resulted from increasing distributed energy systems fed into low voltage grids, voltages of distribution networks fluctuate in a wider and wider range, thereby violating quality requirement of middle voltage grids. Even if the transmission capacity is sufficient, Grid Operators have to construct more distribution power lines in order to mitigate voltage fluctuations. A more cost-effective alternative is found to employ Voltage-Regulated Distribution Transformers (VRDT) that automatically adjust the transformation ratio so that the voltages of middle voltage grids and low voltage grids are decoupled, hence a full exploitation of existing transmission capacity and reduction of the cost of traditional grid reinforcement [47]. All of the big four electricity facility producers (ABB, Siemens, Schneider and GE) have brought VRDT products onto the market. VRDT is now in pilot project phase [48] and nationwide deployment [49]. Applications are found mostly in Germany, where the rapid growth of distributed solar power already forced Grid Operators to either expand power lines or deploy VRDTs.

\section{5) Object management (OM)}

Object Management is an object-oriented program. It checks the availability of the object and translates the command from Operation Layer into a set of signals that the control unit of a specific appliance understands [7].

\section{E. Appliance Layer}

In the Appliance Layer there are all the physical facilities along the chain from energy source to sink, including energy production, conversion, transmission, distribution, storage and consumption. Solar panels, wind turbines, coal power plant, hydro power plants, transmission grid, batteries and heat pumps - the long list of energy facilities is well-known. Energy flows in the Appliance Layer corresponds to the trading flows in the Business Layer. Appliances are controlled through the Interface Layer by market roles in Business Layer in forms of use cases and operations.

\section{SUMMARY}

Energy Internet is a generation of the whole energy sector where a diversity of market roles actively take part in energy transactions and market services to form a competitive market as well as where energy flows are better perceived and controlled by intelligent software and hardware so that dynamic in-time information flows spread from superstructure all the way to the infrastructure and reversely, for the ultimate purpose of an economic, safe and environmentally friendly energy supply and consumption. Various main use cases and technologies in application are categorized with the aid of the architecture of Energy Internet proposed in this work. Review of the use cases and technologies are based on a wide range of sources including academic papers, project reports, policies and press information in order to disclose actual application and deployment status. It is to notice that the present paper by no means covers all the technologies and use cases related to Energy Internet. Rather, the paper seeks for a structural overview of the Energy Internet and aims to provide a few of the most popular technologies in practice. The architecture is open to addition of other use cases and technologies.

\section{REFERENCES}

[1] J. Rifkin, The Third Industrial Revolution: How Lateral Power Is Transforming Energy, the Economy, and the World, New York: St. Martin's Press, 2011.

[2] A. Q. Huang and J. Baliga, "FREEDM system: Role of power electronics and power semiconductors in developing an energy internet," in Proc. 21st International Symposium on Power Semiconductor Devices IC's, 2009.

[3] L. H. Tsoukalas and R. Gao, "From smart grids to an energy internet: Assumptions, architectures and requirements," in Proc. 3rd International Conference on Electric Utility Deregulation and Restructuring and Power Technologies, 2008.

[4] N. Bui, A. P. Castellani, P. Casari et al., "The internet of energy: A web-enabled smart grid system," Network, vol. 26, no. 4, pp. 39-45, 2012.

[5] A. Jung, Smart Grid 2.0: Building the Internet of Energy Supply, Spiegel, 2010.

[6] C. F. Covrig, M. Ardelean, J. Vasiljevska et al., Smart Grid Projects Outlook 2014, Publications Office of the European Union, 2014.

[7] Federal Ministry of Economics and Technology. (2014). Smart energy made in Germany. [Online]. Available: http://www.bmwi.de/BMWi/Redaktion/PDF/Publikationen/smart-ene rgy-made-in-germany,property $=$ pdf, bereich $=$ bmwi2012, sprache $=\mathrm{de}, \mathrm{r}$ wb=true.pdf

[8] V. Giordano and S. Bossart, "Assessing smart grid benefits and impacts: EU and U.S. initiatives," European Commission, US Department of Energy, 2012.

[9] Editorial Office, "State grid corporation of China smart grid program: In three steps complete till 2020," North China Electric Power, vol. 8 , Aug. 2009.

[10] Z. Liu, Global Energy Interconnection, Academic Press, 2015.

[11] Smart Grid Reference Architecture, CEN-CENELEC-ETSI Smart Grid Coordination Group, 2012.

[12] A. Q. Huang, M. L. Crow, G. T. Heydt et al., "The future renewable electric energy delivery and management (FREEDM) system: The energy internet," Proceedings of the IEEE, vol. 99, no. 1, pp. 133-148, 2011.

[13] NIST Framework and Roadmap for Smart Grid Interoperability Standards, National Institute of Standards and Technology, US Department of Commerce 1108R3, 2014.

[14] V. Vlatchkov, "Recommendations for creation of balancing groups and BRP," Deloitte Consulting LLP, 2014.

[15] I. Erlich, M. Wilch, and C. Feltes, "Reactive power generation by DFIG based wind farms with AC grid connection," in Proc. 2007 European Conference on Power Electronics and Applications, 2007.

[16] D. Hölder, "Vermarktung von strom/flexibilität aus EE \& KWK," Clean Energy Sourcing, 2015.

[17] C. W. Gellings, "The concept of demand-side management for electric utilities," Proceedings of the IEEE, vol. 73, no. 10, pp. 1468-1470, 1985.

[18] F. Shariatzadeh, P. Mandal, and A. K. Srivastava, "Demand response for sustainable energy systems: A review, application and implementation strategy," Renewable and Sustainable Energy Reviews, vol. 45, pp. 343-350, 2015.

[19] H. Saboori, M. Mohammadi, and R. Taghe, "Virtual power plant (VPP), definition, concept, components and types," in Proc. Power and Energy Engineering Conference (APPEEC), 2011.

[20] D. Pudjianto, C. Ramsay, and G. Strbac, "Virtual power plant and 
system integration of distributed energy resources," Renewable Power Generation, vol. 1, no. 1, pp. 10-16, 2007.

[21] P. Asmus, "Virtual power plants - global market analysis and forcasts," Navigant Consulting, 2014.

[22] R. Mackensen, K. Rohrig, and H. Emanuel, "Abschlussbericht das regenerative Kombikraftwerk," Agentur für Erneuerbare Energien, 2008.

[23] R. Garcia-Valle and J. A. P. Lopes, Electric Vehicle Integration into Modern Power Networks, Berlin: Springer Science \& Business Media, 2012.

[24] D. Dallinger, R. Kohrs, M. Mierau et al., "Plug-in electric vehicles automated charging control," Fraunhofer ISI, Karlsruhe, Germany, 2015.

[25] N. Gordon-Bloomfield. (2014). Minnesota becomes first U.S. state to mandate special utility tariffs for electric cars. [Online]. Available: https://transportevolved.com/2014/06/13/minnesota-becomes-first-us-state-mandate-special-utility-tariffs-electric-cars/

[26] Y. Mu, J. Wu, J. Ekanayake et al., "Primary frequency response from electric vehicles in the Great Britain power system," IEEE T. Smart Grid, vol. 4, no. 2, pp. 1142-1150, 2013.

[27] IRENE Project Results and Publications. [Online]. Available: http://www.projekt-irene.de/

[28] iZeus - intelligent zero emission urban system. [Online]. Available: http://www.izeus.de/

[29] A. Y. S. Lam, K. C. Leung, and V. O. K. Li, "Capacity estimation for vehicle-to-grid frequency regulation services with smart charging mechanism," IEEE Transactions on Smart Grid, vol. 7, no. 1, 2015.

[30] Energy Management Systems, ISO 50001:2011, 2011.

[31] T. Jyung, K. Jeong, Y. Baek, et al., "The system design and demonstration for autonomous microgrid operation," Journal of Electrical Engineering and Technology, vol. 7, no. 2, pp. 171-177, 2012.

[32] Y. Lim, H. Kim, and T. Kinoshita, "Distributed load-shedding System for agent-based autonomous Microgrid operations," ENERGIES, vol. 7, no. 1 , pp. 385-401, 2014.

[33] A. Kießling, "Verteilte automatisierung im verteilungsnetz," in Smart Energy, H. Servatius, U. Schneidewind, \& D. Rohlfing, Eds. Springer Berlin Heidelberg, 2012, pp. 317-335.

[34] S. Sivanagaraju and G. Sreenivasan, Power System Operation and Control, Chennai, India: Pearson, 2009.

[35] H. Appelrath, Future Energy Grid: Migrationspfade in das Internet der Energie, Berlin: Springer, 2013.

[36] M. Klobasa, M. Ragwitz, F. Sensfuß, et al., "Laufende evaluierung der direktvermark-tung von strom aus erneuerbaren energien," Fraunhofer ISI, 2013.

[37] P. Fox-Penner. (2011). Surprising deployment developments: Smart grid newsletter. IEEE. [Online]. Available: http://smartgrid.ieee.org/august-2011/74-surprising-deployment-devel opments

[38] Smart Energy Demand Coalition, "Mapping demand response in Europe today," Brussels, 2014.

[39] W. Kempton, V. Udo, K. Huber, et al., "A test of Vehicle-to-Grid (V2G) for Energy storage and frequency regulation in the PJM system," University of Delaware, Green Mountain College, PJM Interconnect, Pepco Holdings, Inc., 2008.

[40] J. A. Short, D. G. Infield, and L. L. Freris, "Stabilization of grid frequency through dynamic demand control," IEEE Transactions on Power Systems, vol. 22, no. 3, pp. 1284-1293, 2007.

[41] B. J. Kirby, "Frequency regulation basics and trends," US Department of Energy, 2004.

[42] A. Sternberg and A. Bardow, "Power-to-What? Environmental assessment of energy storage systems," Energy Environ. Sci., vol. 8, no. 2, pp. 389-400, 2015.

[43] R. van Gerwen, S. Jaarsma, and R. Wilhite, "Smart metering," KEMA Labortories, 2006.

[44] S. J. J. Y. Q. Huang, Innovative Testing and Measurement Solutions for Smart Grid, New York: John Wiley \& Sons, 2015.

[45] T. Rauhala, K. Saarinen, M. Latvala, et al., "Applications of phasor measurement units and wide-area measurement system in Finland," 2011 IEEE Trondheim PowerTech, 2011.

[46] MVV binden PV-Park in Direktvermarktung ein: Zeitung für kommunale Wirtschaft, Munich, 2013.

[47] M. Haslbeck, M. Sojer, T. Smolka, et al., "Mehr Netzanschlusskapazität durch regelbare Ortsnetztransformatoren," Verband der Elektrotechnik Elektronik Informationstechnik e.V., 2012.

[48] C. Kroener, M. Hennig, R. Schmid, et al., "Gaining experience with a regulated distribution transformer in a smart grid environment," in Proc. CIRED 2012 Workshop on Integration of Renewables into the Distribution Grid, 2012.

[49] E.ON Press. (May 2014). E.ON to install 180 new voltage-regulated distribution transformers by the end of 2014. [Online]. Available http://www.eon.com/en/media/news/press-releases/2014/5/27/eon-to-i nstall-180-new-voltage-regulated-distribution-transforms-by-the-endof-2014.html

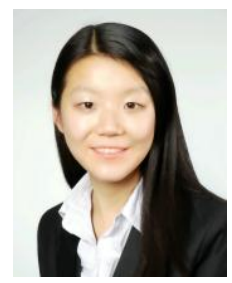

Yingya Zhou was born in Shanghai, China. She received her B.Sc. degree in power engineering and automation from Tsinghua University, Beijing, China in 2012 .

She is currently a M.Sc. student in power engineering at Tsinghua University and a M.Sc. student in production systems engineering at RWTH Aachen University, Germany. She is also the global coordinator of Working Group Energy Internet at Chinese Association of Renewable Energy in Germany e.V. as well as the department leader of Energy Network and German Energy Research Databank in Aachen, Germany. Her main research interests include big data in energy sector, energy internet and worldwide technology trends.

Ms. Zhou is the author of more than 40 patents and publications.

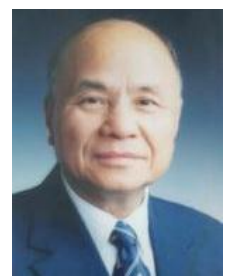

Weidou Ni was born in Ningbo, China. He received his $\mathrm{PhD}$ degree in power engineering from Kalining Polytechnic Institute of Leningrad, USSR in 1962 and was entitled to honorable doctor of science from the Saint Petersburg Polytechnical University in 1990.

$\mathrm{He}$ is a professor at the Energy Department of Tsinghua University, China and chairman of Tsinghua-BP Clean Energy Research and Education Center. His research interests include diagnostics of large power plants, energy strategy and policy.

Prof. Ni is a senior academician of the Chinese Academy of Engineering, vice-chairman of the Beijing Association for Science and Technology and member of International Academy of Higher Education. Ni is also a leader and senior advisor of energy strategy, technology, policy for Chinese government.

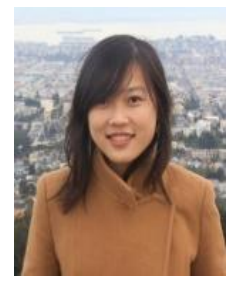

Zhao Zhu was born in Shanghai, China. She received her B.Sc. degree in power engineering and automation from Tsinghua University, Beijing, China in 2014 and her M.Phil. degree in technology policy from Cambridge University, UK in 2015.

She is currently a M.Sc. student in management studies in MIT Sloan School of Management, US. Her main research interests include solar PV and thermal market in China, energy internet and natural gas market.

Ms. Zhu is the author of electricity generation costs of concentrated solar power technologies in China based on operational plants in Energy Journal. 


\section{Energy Management}


